\title{
ECUADORIAN QUINOA (CHENOPODIUM QUINOA WILLD) FATTY ACIDS PROFILE
}

\author{
ALTUNA JL ${ }^{1}$, SILVA M² ${ }^{2}$ ÁLVAREZ M², QUINTEROS MF ${ }^{1}$, MORALES $\mathbf{D}^{2}$, CARRILLO $\mathbf{W}^{1,2 *}$
}

${ }^{1}$ Department of Research, Faculty of Agricultural Sciences, Natural Resources and the Environment, Bolıvar State University, Av. Ernesto Che Guevara s/n- Av. Gabriel Secaira, (CP 020150), Guaranda, Ecuador. ${ }^{2}$ Laboratory of Functional Foods, Faculty of Foods Science and Engineering, Technical University of Ambato. Av. Los Chasquis y Rio Payamino, Campus Huachi, (CP 1801334) Ambato, Ecuador. Email: wi.carrillo@uta.edu.ec

Received: 16 April 2018, Revised and Accepted: 4 June 2018

\section{ABSTRACT}

Objective: The aim of this study was to determine the methyl esters fatty acids (FAMEs) profile of quinoa seeds (Chenopodium quinoa Willd) of a sample cultivated in Guaranda, Ecuador.

Methods: Quinoa oil was obtained from quinoa seeds using the Soxhlet method. FAMEs identification and quantification were carried out using the gas chromatography (GC) with a mass spectrometry (MS), using the database Library NIST14.L to identify the fatty acids present in quinoa oil.

Results: Quinoa oil from Ecuador was analyzed by GC-MS, to obtain four majoritarian fatty acids, palmitic acid (10.66\%), oleic acid (24.70\%), linoleic acid (62.47\%), and linolenic acid (2.19\%). Omega 6 was the most abundant fatty acid in quinoa oil. Quinoa oil has a good proportion of oleic acid and linoleic acid.

Conclusions: Quinoa seeds present a good proportion of fatty acids. These seeds can be used in the food industry for different purposes to enjoy their fatty acids composition. Regular consumption of quinoa can improve health.

Keywords: Quinoa, Chenopodium quinoa Willd, Fatty acids, Methyl esters fatty acids, lipids.

(C) 2018 The Authors. Published by Innovare Academic Sciences Pvt Ltd. This is an open access article under the CC BY license (http://creativecommons. org/licenses/by/4. 0/) DOI: http://dx.doi.org/10.22159/ajpcr.2018.v11i11.24889

\section{INTRODUCTION}

Quinoa (Chenopodium quinoa Willd) is an Andean pseudocereal plant of the Amaranthaceae family. Quinoa is considered one of the grains of the $21^{\text {st }}$ century [1-3] for their agronomic characteristics and nutritive and biological properties. Quinoa has been cultivated and consumed for the past 5000-7000 years by the indigenous Andean region populations. The indigenous considered quinoa as the sacred "mother grain." Quinoa seeds have been introduced as a gourmet food in international markets and their exports have experienced an increase from 5000 to 40,000 tons in the last years, increasing then production in these countries. C. quinoa plants are cultivated in vast areas and sustain the traditional economy of small growers who cultivate multiple varieties in these countries $[4,5]$.

In the Andean region, the most common use of quinoa is the consumption of the seeds. Quinoa seed presents a protein content ranging from $12.5 \%$ to $16.5 \%$, a fat content ranging from $5.5 \%$ to $8.5 \%$, $3.0-3.8 \%$ of ash content, carbohydrate content of $60.0-74.7 \%$, and a total crude fiber ranging $1.92-10.5 \%$. Unsaturated fatty acids of quinoa seeds have been described by different authors with values of $23.3 \%$, $26.0 \%$, and $24.8 \%$ of oleic acid (omega 9); $53.1 \%, 50.2 \%$, and $52.3 \%$ of linoleic acid (omega 6); and $6.2 \%, 4.8 \%$, and $3.9 \%$ of linolenic acid (omega 3) [6-8]. Omega 3 and omega 6 are called "essential fatty acids" or EFAs, as they are not synthesized by the human body. They need to be included in the diet for this reason. The main saturated fatty acid is the palmitic acid with reported values ranging from $8.85 \%, 11.0 \%$, and $9.0 \%[9-11]$

Quinoa oil has a remarkable stability against oxidation due to the presence of a high content of the $\alpha$-tocopherol component $[12,13]$. The aim of this study was to characterize the composition of fatty acids methyl esters (FAMEs) present in quinoa oil samples cultivated in Ecuador using the gas chromatography mass spectrometry detector (GC-MSD).

\section{METHODS}

\section{Oil extraction}

Quinoa (C. quinoa Willd) was obtained from a quinoa germplasm bank at the State Bolivar University, campus Alpachaca, Guaranda, Ecuador. Quinoa oil sample was obtained using a Soxhlet apparatus for approximately $5 \mathrm{~h}$ with hexane as solvent, with a solid to solvent ratio of $1 / 7 \mathrm{~m} / \mathrm{v}$. After the extraction process, the flask contents were filtered, and the liquid fraction containing the lipid extract and solvent was poured into a 250 -mL flask of a rotary film evaporator to remove the solvent. The oil was collected, evaporated under nitrogen, weighed, and stored in sealed amber glass vials at $-20^{\circ} \mathrm{C}$ until analysis [14].

\section{Fatty acids analysis by GC-MSD}

Quinoa seeds oil fatty acid composition was analyzed by injecting fatty acid methyl esters $[15,16]$ into an Agilent Technologies 7980A system GC (Agilent, Santa Clara, CA) equipped with a MSD 5977A GC/MSD, an auto-sampler 7693, column $(60 \mathrm{~m} \times 250 \mu \mathrm{m} \times 0.25 \mu \mathrm{m}$, Agilent $122-7062)$. The oven temperature ramp 2 : at $200^{\circ} \mathrm{C}$ at $25^{\circ} \mathrm{C} / \mathrm{min}$ for $10 \mathrm{~min}$ and ramp 3: at $250^{\circ} \mathrm{C}$ at $2^{\circ} \mathrm{C} / \mathrm{min}$. The injector and detector temperatures were set at $250^{\circ} \mathrm{C}$. Helium was used as carrier gas at a linear flow velocity of $1.4 \mathrm{~mL} / \mathrm{min}$.

\section{RESULTS}

Quinoa seeds (C. quinoa Willd) were obtained of a cultivar of the faculty of agricultural sciences, natural resources, and the environment of the State Bolivar University in Guaranda, Ecuador. Quinoa seeds were collected manually by the university employees (Fig. 1).

FAMEs from quinoa oil (C. quinoa Willd) were analyzed by GC-MS and the identification of fatty acids was made using the spectrum of a database Library NIST14.L. The chromatogram of GC presents four abundant peaks which were separated with an excellent resolution of each peak with the help of a column Agilent DB-WAX 122-7062. 
These peaks presented in the chromatogram were identified using the spectrum of the library. The first peak presented a retention time of 13.976 min and was identified as C16:0, the second peak presented a retention time of $17.218 \mathrm{~min}$ and was identified as C18:1, the third peak presented a retention time of $18.389 \mathrm{~min}$ and was identified as C18:2, and finally, the fourth peak presented a retention time of $19.911 \mathrm{~min}$ and was identified as C18:3. The separation and definition of the four peaks were excellent in the GC chromatogram (Fig. 2).

The concentration of FAMEs present in quinoa seeds was determined using the peak area ratio. Table 1 shows the percentage of main quinoa oil fatty acids. C16:0 with a value of $10.66 \%$ of palmitic acid total content, C18:1 with a value of $24.70 \%$ of oleic acid total content, C18:2 with a value of $62.47 \%$ of linoleic acid total content, and C18:3 with a value of $2.19 \%$ of linolenic acid total content. Quinoa oil from Ecuador presents a high content of unsaturated fatty acids, such as oleic acid and linoleic acid.

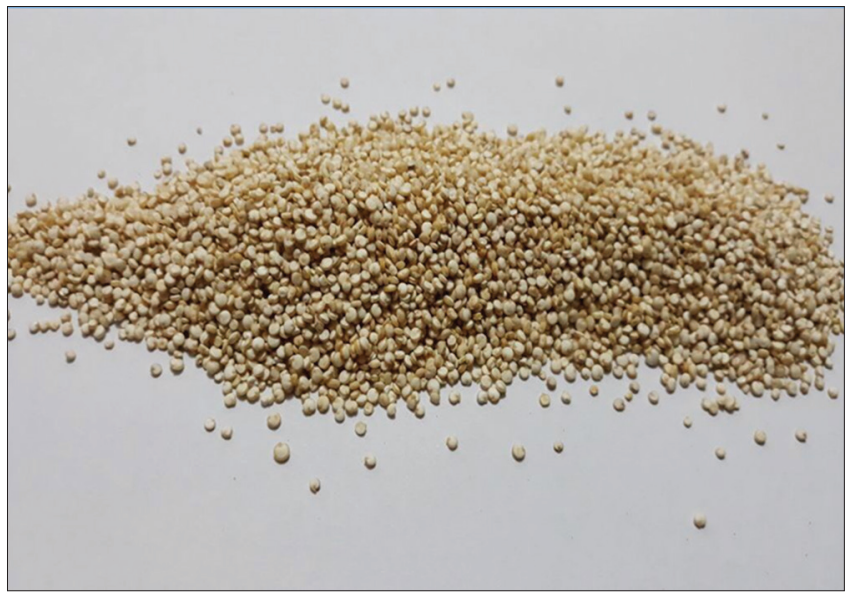

Fig. 1: Quinoa seeds (Chenopodium quinoa Willd) from Ecuador

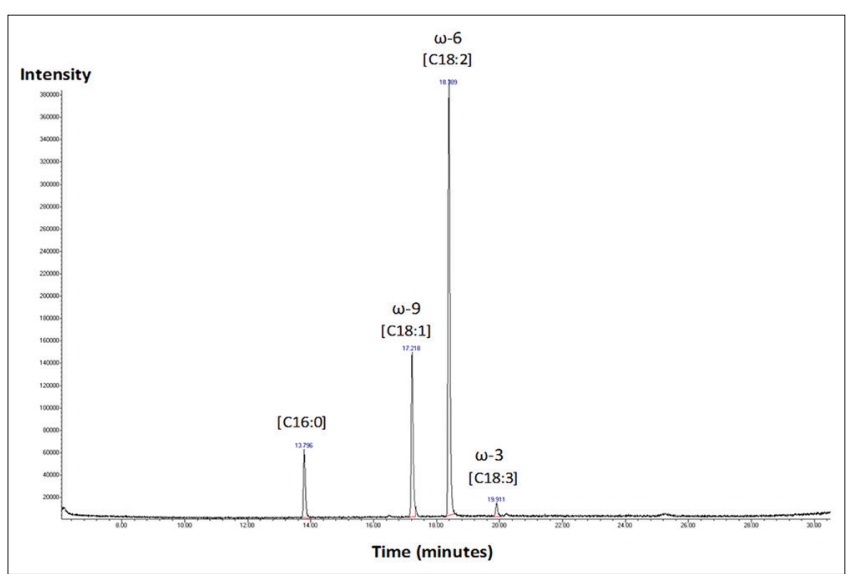

Fig. 2: Gas chromatography chromatogram of methyl esters fatty acids of quinoa oil from Ecuador
Fig. 3a-d shows typical mass spectrum of palmitic acid, oleic acid, linoleic acid, and linolenic acid. They present typical fragmentation of ions in the mass spectrum. These mass spectrums were used to identify the structural formula and chemical name of fatty acids present in quinoa (Chenopodium quinoa Willd).

\section{DISCUSSION}

Quinoa is a pseudocereal with an oil content value from $1.8 \%$ to $9.5 \%$ depending of the variety of the crop. Quinoa grains have a higher content of oil than typical cereals such as maize $(3-4 \%)$, white rice $(0.66 \%)$, brown rice $(2.92 \%)$, and wheat $(1.54 \%)$ [5]. Consumption of vegetal oil is high in the world, as these oils can have a good balance of essential fatty acids "EFAs" and non-essential fatty acids "NEFAs." Many fatty acids are synthesized by the human body, and these are known as "non-essential fatty acids" because they are not essentially needed in the diet. However, human body cannot produce EFAs, such as linoleic acid and linolenic acid, these EFAs need to be introduced in the diet $[17,18]$. EFAs can be grouped in two families called omega $3(\omega-3)$ and omega $6(\omega-6)$ [19]. Linoleic acid (omega 6) is the polyunsaturated fatty acid most abundant in quinoa oil in this study, the value reported was $62.47 \%$ of linoleic acid, being this value in accordance with data previously reported by different authors such as Peiretti et al. (2013) [20], Tang et al. (2015) [21], and Pelligrini et al. (2018) [22]. Pelligrini et al. (2018) reported the content of linoleic acid in six different quinoas obtained in Bolivia and Peru with values of $48.76 \%, 49.66 \%, 50.16 \%, 50.89 \%, 52.44 \%$, and $53.94 \%$ [22]. The value reported in this study of linoleic acid is $62.47 \%$, higher than the value reported by Pelligrini et al. (2018) [22]. Fat is an important component of the diet and plays a crucial role in the regulation of plasma cholesterol levels [23]. Different studies support the idea that a diet rich in vegetable oil with a high content of linoleic acid (omega 6) can help to produce a hypocholesterolemic effect. Common vegetable oils rich in linoleic acids such as corn (52.68\%), sunflower (56.5\%), and soybean $(53.7 \%)$ have a hypocholesterolemic effect already reported in animal and human studies [24,25]. The profile of quinoa oil is similar to the profile reported for corn oil, sunflower oil, and soybean oil with a high content of polyunsaturated fatty acids, with a percentage of linoleic acid in quinoa higher that values reported in these three vegetable oils. Regular consumption of quinoa seeds in the diet can be healthy and can reduce the cardiovascular risk.

\section{ACKNOWLEDGMENTS}

This study was supported by Universidad Técnica de Ambato, Ecuador (Project CPU-1373-2014-UTA) and (Project Canje de Deuda EspañaEcuador). This work has been reviewed in the English edition by Emilio Labrador.

\section{AUTHOR CONTRIBUTIONS}

Carrillo W, Altuna JL, Quinteros MF, and Morales D conceived and designed the experiments. Silva M and Alvarez M performed the gas chromatography analyses. Carrillo $\mathrm{W}$ wrote the paper.

\section{CONFLICTS OF INTEREST}

The authors declare no conflicts of interest.

Table 1: Fatty acid composition of quinoa seeds from Ecuador by GC/MS analysis

\begin{tabular}{llll}
\hline Retentions time & FAMEs & Chemical name & $\mathbf{N}^{\circ}$ carbons \\
\hline $13.796 \mathrm{~min}$ & Palmitic acid & Hexadecanoic acid & $\mathrm{C} 16: 0$ \\
$17.218 \mathrm{~min}$ & Oleic acid & Cis-9-octadecenoic acid & $\mathrm{C} 18: 1$ \\
$18.389 \mathrm{~min}$ & Linoleic acid & 9,12 -octadecadienoic acid & $\mathrm{C} 18: 2$ \\
$19.911 \mathrm{~min}$ & Linolenic acid & Octadeca-9,12,15 - Trienoic acid & $\mathrm{C} 18: 3$ \\
Saturated & & & $62.47 \pm 0.75$ \\
Monounsaturated & & & $2.19 \pm 0.10$ \\
Polyunsaturated & & & \\
\hline
\end{tabular}

GC/MS: Gas chromatography/mass spectrometry, FAMEs: Methyl esters fatty acids. Data are expressed as the mean \pm standard deviation (n=3) 


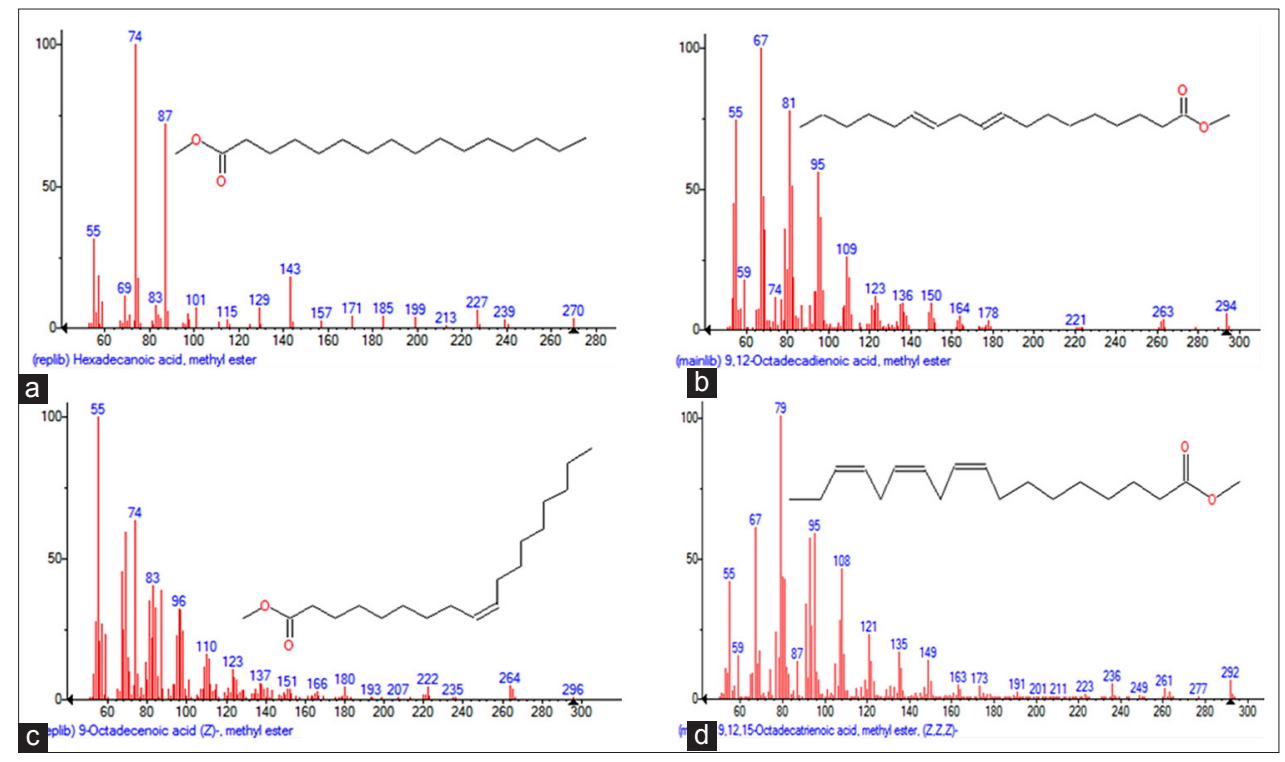

Fig. 3: (a) Mass spectrum of palmitic acid, (b) mass spectrum of oleic acid, (c) mass spectrum of linoleic acid, and (d) mass spectrum of linolenic acid

\section{REFERENCES}

1. Vilcacundo R, Miralles B, Carrillo W, Hernández-Ledesma B. In vitro chemopreventive properties of peptides released from Quinoa (Chenopodium quinoa willd.) protein under simulated gastrointestinal digestion. Food Res Int 2018;105:403-11.

2. Vilcacundo R, Barrio D, Carpio C, García-Ruiz A, Rúales J, HernándezLedesma B, et al. Digestibility of Quinoa (Chenopodium quinoa willd.) protein concentrate and its potential to inhibit lipid peroxidation in the zebrafish larvae model. Plant Foods Hum Nutr 2017;72:294-300.

3. Vilcacundo R, Miralles B, Carrillo W, Hernández-Ledesma, B. In vitro chemopreventive properties of peptides released from quinoa (Chenopodium quinoa Willd.) protein under simulated gastrointestinal digestion. Food Res Int 2018;105:403-11.

4. Toapanta A, Carpio C, Vilcacundo R, Carrillo, W. Analysis of protein isolate from Quinoa (Chenopodium quinoa Willd). Asian J Pharm Clin Res 2016;9:332-4

5. Vega-Gálvez A, Miranda M, Vergara J, Uribe E, Puente L, Martínez EA, et al. Nutrition facts and functional potential of Quinoa (Chenopodium quinoa willd.), an ancient andean grain: A review. J Sci Food Agric 2010;90:2541-7.

6. Kozioł M. Chemical composition and nutritional evaluation of Quinoa (Chenopodium quinoa Willd). J Food Comp Anal 1992;5:35-68.

7. Ruales J, Nair BM. Properties of starch and dietary fibre in raw and processed Quinoa (Chenopodium quinoa, willd) seeds. Plant Foods Hum Nutr 1994;45:223-46.

8. Repo-Carrasco R, Espinoza C and Jacobsen SE. Nutritional value and use of the Andean crops Quinoa (Chenopodium quinoa) and Kañiwa (Chenopodium pallidicaule). Food Rev Int 2003;19:179-89.

9. Arumugam M, Raman M, Eagappan K. Formulation and storage stability of beta carotene enriched vitamin $\mathrm{d} 3$ and omega 3 fortified cold pressed virgin coconut oil. Int J Pharm Pharm Sci 2014;6:112-6.

10. Zambiazi RC, Przybylski R, Zambiazi MW, Mendonça CB. Fatty acid composition of vegetable oils and fats. B. CEPPA Curitiba 2007;25:111-20.

11. Encina-Zelada C, Cadavez V, Pereda J, Gómez-Pando L, Salvá-Ruíz B, Teixeira JA, et al. Estimation of composition of Quinoa (Chenopodium quinoa Willd.) grains by near-infrared Transmission spectroscopy. LWT Food Sci Technol 2017;79:126-34

12. Escribano J, Cabanes J, Jiménez-Atiénzar M, Ibañez-Tremolada M, Gómez-Pando L. R, García-Carmona F, et al. Characterization of betalains, saponins and antioxidant power in differently colored Quinoa (Chenopodium quinoa) varieties. Food Chem 2017;234:285-94.
13. Matsuo M. In vivo antioxidant activity of methanol extract from quinoa fermented with Rhizopus oligosporus. J Nutr Sci Vitaminol (Tokyo) 2005;51:449-52

14. Carrillo W, Carpio C, Morales D, Vilcacundo E, Alvarez M. Fatty acids composition in macadamia seeds oil (Macadamia intergrifolia) from Ecuador. Asian J Pharm Clin Res 2017;10:303-6.

15. Carrillo W, Carpio C, Morales D, Vilcacundo E, Alvarez M, Silva M. Content of fatty acids in corn (Zea mays L.) oil from Ecuador. Asian J Pharm Clin Res 2007;10:150-3.

16. Lara D, Vilcacundo E, Carrillo C, Carpio C, Silva M, Alvarez M, et al. Obtention of protein concentrate and polyphenols from macadamia (Macadamia integrifolia) with aqueous extraction method. Asian J Pharm Clin Res 2017;10:138-42.

17. Moyad MA. An introduction to dietary/supplemental omega-3 fatty acids for general health and prevention. Part I. Urol Oncol 2005;23:28-35.

18. Carrillo W, Carpio C, Morales D, Álvarez M, Silva M. Fatty acids content in ungurahua oil (Oenocarpus bataua) from Ecuador. Findings on adulteration of ungurahua oil in Ecuador. Asian J Pharm Clin Res 2018;11:389-91.

19. Dhifi W, Khedher M, Bellili S, Sadaka C, Wakim L, Beyrouthy M, et al. Effects of olive drying and storage on the oxidative status, aroma, chlorophyll and fatty acids composition of olive oil. Int J Pharm Pharm Sci 2014;7:102-8.

20. Peiretti PG, Gai F, Tassone S. Fatty acid profile and nutritive value of Quinoa (Chenopodium quinoa Willd.) seeds and plants at different growth stages. Anim Feed Sci Technol 2013;183:56-61.

21. Tang Y, Li X, Chen PX, Zhang B, Hernandez M, Zhang H, et al. Characterisation of fatty acid, carotenoid, tocopherol/tocotrienol compositions and antioxidant activities in seeds of three Chenopodium quinoa willd. Genotypes. Food Chem 2015;174:502-8.

22. Pellegrini M, Lucas-Gonzales R, Ricci A, Fontecha J, FernándezLópez J, Pérez-Álvarez JA, et al. Chemical, fatty acid, polyphenolic profile, techno-functional and antioxidant properties of flours obtained from quinoa (Chenopodium quinoa Willd) seeds. Ind Crops Prod 2018;111:38-46

23. Most MM, Tulley R, Morales S, Lefevre M. Rice bran oil, not fiber, lowers cholesterol in humans. Am J Clin Nutr 2005;81:64-8.

24. Sugano M, Tsuji E. Rice bran oil and cholesterol metabolism. J Nutr 1997;127:521S-4.

25. Wilson TA, Ausman LM, Lawton CW, Hegsted DM, Nicolosi RJ. Comparative cholesterol lowering properties of vegetable oils: Beyond fatty acids. J Am Coll Nutr 2000;19:601-7. 